\title{
Redundancy Strategies for a High Splitting Optically Amplified Passive Optical Network
}

\author{
A. J. Phillips, J. M. Senior, R. Mercinelli, M. Valvo, P. J. Vetter, C. M. Martin, M. O. van Deventer, P. Vaes, and \\ X. Z. Qiu
}

\begin{abstract}
High splitting, optically amplified, passive optical networks (SuperPONs) are investigated in terms of redundancy provision and protection mechanisms. Options for redundancy, including the important special case of dual homing, are detailed, and it is determined as to which of these options (duplication of the feeder and first distribution section, and $N+1$ protection of the optical amplifiers in the amplified splitter) would be required to be provided to all attached users to facilitate appropriate availability of the basic telephony service. The distributed amplified splitter dual homing solution is found to outperform the single amplified splitter solution in terms of its survivability. The protection mechanisms necessary to automatically switch to the redundant provision are discussed and it is seen that with the aid of suitable regular precautionary procedures protection switching can generally be provided rapidly $(<50 \mathrm{~ms})$. Finally an availability, and cost versus availability, study confirms the aforementioned redundancy assessment for fiber-to-the-home (FTTH) implementations, but shows fiber-to-the-curb (FTTC) as needing additional redundancy.
\end{abstract}

Index Terms-Access network, availability, dual homing, optical amplification, protection switching, redundancy, super passive optical network (SuperPON).

\section{INTRODUCTION}

$\mathbf{I}$ N BROAD-BAND telecommunication networks it has been possible to identify a general trend in which the relative cost of signal transport is decreasing more rapidly than the cost of switching. This provides the motivation for a node consolidation, whereby the number of switching nodes is reduced, leading to access networks covering greater ranges and serving larger user populations. An access system that potentially benefits from the reduced investment and exploitation costs obtained by node consolidation is a high splitting, optically amplified, passive optical network (SuperPON) [1]. Such systems have been under investigation and development by the Photonic Local Access Network (PLANET) consortium of the European

Manuscript received November 10, 1999; revised October 17, 2000. This work was supported by the European Commission within the ACTS Project AC050 Photonic Local Access Networks (PLANET).

A. J. Phillips is with the Centre for Communication Networks Research, Department of Engineering and Technology, The Manchester Metropolitan University, Manchester, U.K.

J. M. Senior is with the Faculty of Engineering and Information Sciences, University of Hertfordshire, Hatfield, U.K.

R. Mercinilli and M. Valvo are with the Centro Studi e Laboratori Telecomunicazioni S.p.A. (CSELT), Torino, Italy.

P. J. Vetter and C. M. Martin are with the Alcatel Corporate Research Center, Antwerpen, Belgium.

M. O. van Deventer is with the KPN Research, Leidschendam, The Netherlands.

P. Vaes and X. Z. Qiu are with the IMEC, University of Gent, Gent,Belgium. Publisher Item Identifier S 0733-8724(01)00742-3.
Union Advanced Communications Technologies and Services (ACTS) program. The aim of this paper is to investigate the provision of redundancy within such a SuperPON system, in order to enable it to meet the availability and survivability criteria which will be delineated later.

The aim of PLANET was to define a cost-effective full-service optical access network, based on the SuperPON concept, which would accommodate specific service requirements within telecommunications in the next decade. To meet the requirement for a greater range, SuperPONs were designed to reach a nominal range of $100 \mathrm{~km}$ (though greater distances are possible with the use of further optical amplifiers [2]) and to support 2048 optical network units (ONU), both considerably exceeding the specification of conventional PONs. Data rates of $2.5 \mathrm{~Gb} / \mathrm{s}$ downstream and $311 \mathrm{Mb} / \mathrm{s}$ upstream were chosen for the trial network, enabling a broadband service basket to be offered to a total of 15000 living units [3] [passed in a fiber-to-the-curb (FTTC) configuration]. The transport system is based on asynchronous transfer mode (ATM) cells using time division multiplexing (TDM) downstream and time division multiple access (TDMA) upstream, similar to the more conventional APON (ATM over PON) systems being considered within the Full Services Access Network (FSAN) initiative [4]. The challenges of developing a medium access control (MAC) protocol for such a large PON are described in [5]. Ranging over such advanced PONs, with the greater range and larger user population, also involves new challenges [6], [7]. Although redundancy and protection for conventional APONs has been considered both in the standards [8], and more recently in the literature [9], they are considerably more complex in the SuperPON case considered herein.

In the next section, the SuperPON system developed by the PLANET consortium is introduced, focusing on a semiconductor optical amplifier (SOA) based solution. In Section III, the resilience requirements for the access network are delineated, whilst various options for redundancy in order to meet them are described in Section IV. Dual homing of SuperPON systems is discussed in Section V and the mechanisms used to implement the various protection strategies are detailed in Section VI. Availability and cost versus availability are addressed in Section VII.

\section{SUPERPON SYSTEMS}

Fig. 1 shows the outline of the generalized PLANET SuperPON system. In essence the system consists of an optical line termination (OLT), which contains the controlling electronics for the SuperPON system together with its laser transmitter and 


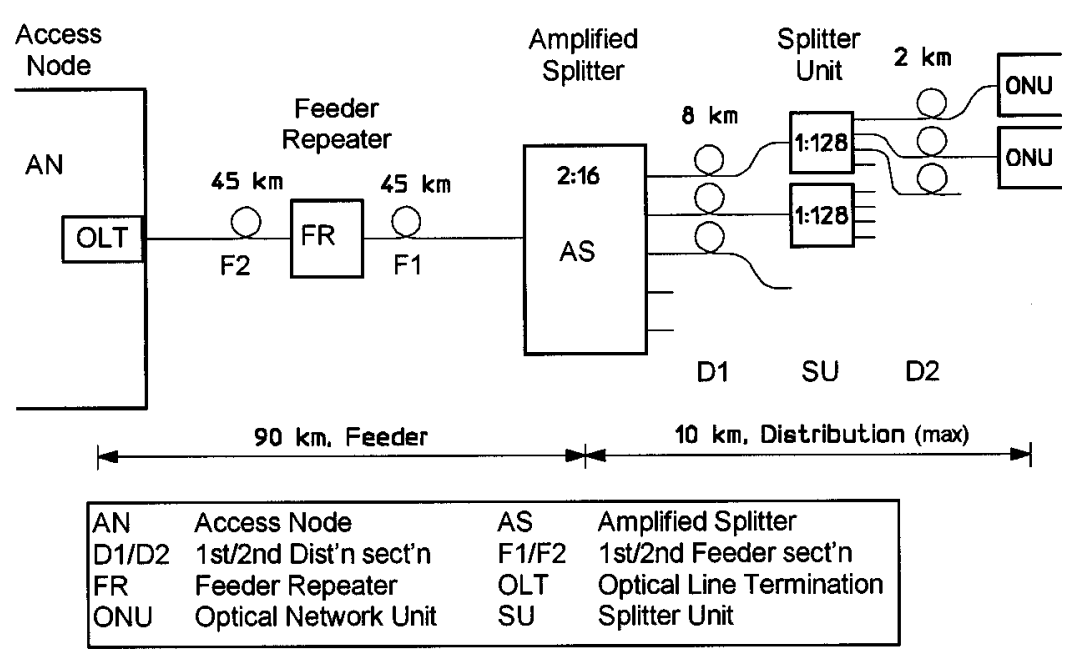

Fig. 1. General PLANET SuperPON architecture.

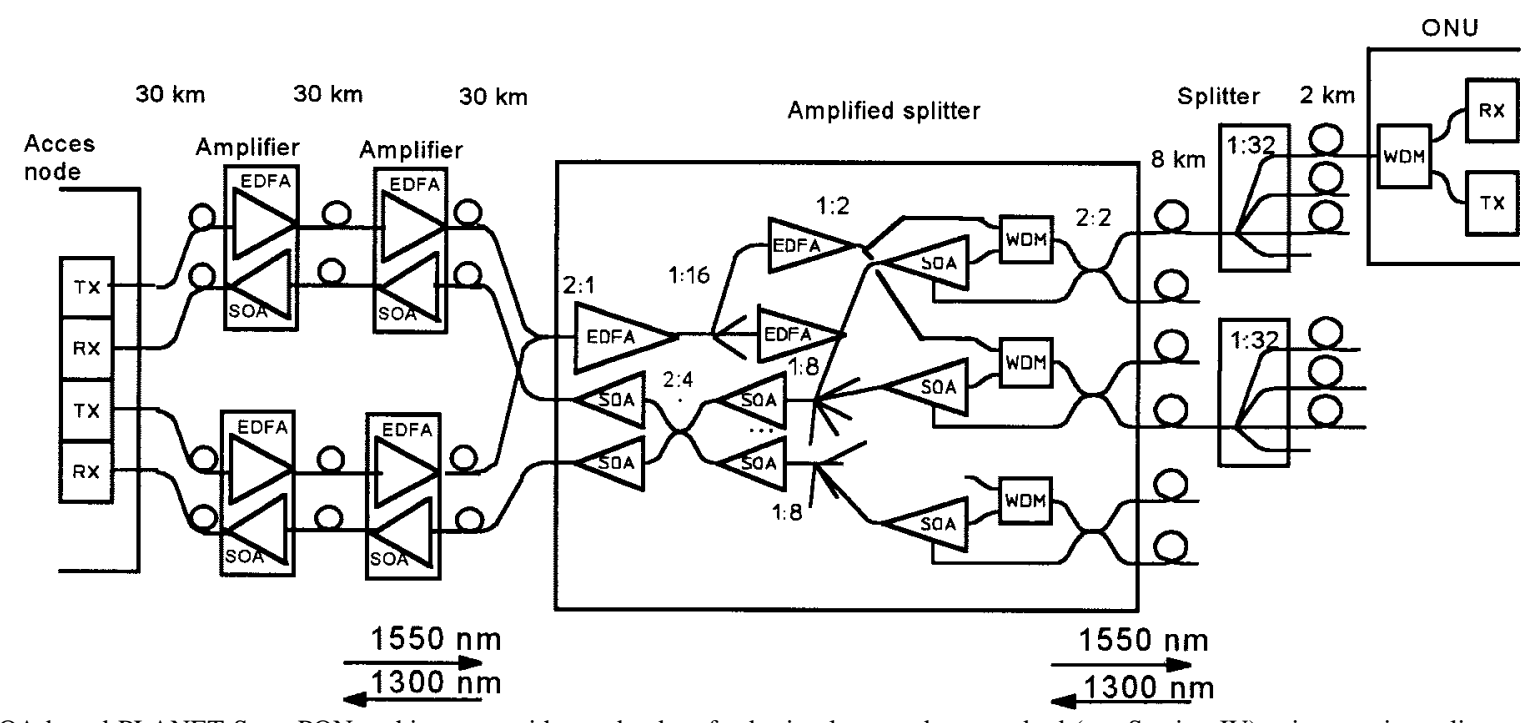

Fig. 2. SOA-based PLANET SuperPON architecture, with a redundant feeder implemented as standard (see Section IV) using passive splitter technology as opposed to the optical switches proposed later.

burst mode receiver, housed in an access node (which may contain OLTs of many different SuperPON systems), connected by a feeder fiber cable to an amplified splitter (AS) unit. The feeder may be extended into multiple fiber sections (F1, F2, etc.) using one or more feeder repeater (FR) units. The first distribution section (D1) connects the AS to a number of passive splitting units (SU), which in turn are connected to the ONUs by the second distribution section (D2). ONUs may be located in a fiber-to-the-home/premises (FTTH/P) configuration or in a curb unit concentrating several subscribers (FTTC) with a very high bit rate digital subscriber loop (VDSL) copper drop to the network termination (NT) in each home [4]. A possible evolution scenario from the current telephony network toward SuperPON based ultrabroad-band access networks is presented in [10]. After such an evolution path the SuperPON access node (AN) will be located at the same building as the transit office/switch in current networks, while the SuperPON AS will be located in a position analogous to current local offices.

The most important physical layer difference between conventional APONs and SuperPONs is the use of optical amplifiers (OA). A wavelength of $1550 \mathrm{~nm}$ (with narrow-line DFB laser transmitters to avoid dispersion penalties) was chosen for downstream transmission to exploit the low fiber loss and to enable the use of high performance erbium-doped fiber amplifiers (EDFA). Upstream optical amplification is complicated by the "noise-funneling" effect [2]. In the upstream optical splitters serve as signal combiners. However, the amplified spontaneous emission (ASE) noise from parallel optical amplifiers is potentially also combined, severely degrading the signal-tonoise ratio (SNR). One solution to this problem is to employ "burst mode operation" of the parallel optical amplifiers, requiring them to be switched "ON" when they are to amplify an ATM cell but to be turned "OFF" otherwise. The speed required for this switching solution requires SOAs, with their short time constant, to be used in the upstream-by comparison EDFAs have very slow gain dynamics. The switchable SOAs were controlled via the MAC-protocol and also offer the possibility of cell-by-cell automatic gain control to reduce the signal dynamic range [11]. PThis solution is considered exclusively within this paper, though other architectural solutions have also been investigated, characterized by differing approaches to the upstream of the system (based on upstream EDFAs or O/E/O regeneration) [12], [13]. A possible configuration of the SOA solution is shown in Fig. 2, though it should be noted that there is 
TABLE I

Reouired SERVICE AND ACCESS Network AvaILABILITY

\begin{tabular}{l|l|l|l}
\hline Service & $\begin{array}{l}\text { Required service } \\
\text { availability }\end{array}$ & $\begin{array}{l}\text { Access network } \\
\text { availability }\end{array}$ & $\begin{array}{l}\text { Access network } \\
\text { MDT }\end{array}$ \\
\hline Leased lines & up to $99.98 \%$ & up to $99.99 \%$ & $53 \mathrm{~min} /$ year \\
\hline Telephony (+fax) & $99.90 \%$ & $99.95 \%$ & $263 \mathrm{~min} / \mathrm{year}$ \\
\hline Other services & $99.0 \%$ & $99.5 \%$ & $2630 \mathrm{~min} / \mathrm{year}$ \\
\hline
\end{tabular}

flexibility in the splitting arrangements, optical amplifier numbers, and positioning, etc. Furthermore, the $10 \mathrm{~km}$ distribution is an upper limit, given the splitting ratio considered, while the feeder can potentially be significantly longer. To enable bidirectional transmission over a single fiber in the distribution section, an upstream wavelength of $1310 \mathrm{~nm}$ was chosen and a $1310 / 1550 \mathrm{~nm}$ diplexer implemented at the ONU. In the feeder, two fiber working was implemented to avoid the loss of WDM duplexers (otherwise required either side of the optical amplifiers) and any bidirectional crosstalk penalties. The upstream burst mode transmitters at the ONUs were DFB lasers with 10 $\mathrm{nm}$ wavelength stability.

\section{RESILIENCE REQUIREMENTS}

The SuperPON network was required to be resilient to failure. Hence, it must have both a high availability and a high survivability. The following resilience requirements apply to SuperPONs from the user viewpoint:

R1) SuperPON services should exhibit sufficient availability.

R2) In the case of mains power failure, the telephony service should remain available.

R3) The time to service recovery after a failure should be limited.

Additionally, from the perspective of the network operator:

R4) No large group of users should be connected to a single-point-of-failure.

Requirement R1) is studied in detail later in this paper. Ideally the access network should achieve a mean down time (MDT) of $53 \mathrm{~min} / \mathrm{y}$, but this can be relaxed for telephony to $263 \mathrm{~min} / \mathrm{y}$, and for multimedia services to $2630 \mathrm{~min} / \mathrm{y}$ (see Table I). Since it is generally vital that the network operator provides the user with a viable telephony service, we define the normal redundancy requirement as that level of redundancy that enables the availability for telephony to be met, for the maximum range $\mathrm{Su}$ perPON in a FTTH configuration. However, FTTC may need additional protection, whilst some urban applications of the $\mathrm{Su}$ perPON may dispense with all the redundancy apart from that of the feeder. The availability of the highest-grade leased line is not easily achieved by a SuperPON without either improvements in the operator's repair intervention policy or additional redundancy, beyond the normal redundancy requirement, in the distribution section and/or at the customer end, for which the potential leased line customer would pay extra. It is very important to note that this also applies to any tree and branch topology access network system, since the main failure contribution comes from the cable plant. The availability criteria that must be applied to the access system are twice as stringent as those required for the service overall, since one has to account for both ends of the connection. It is also assumed that the core network has enough redundancy to make its MDT contribution negligible. It should be noted that, relative to a conventional APON, the presence of optical amplifiers, alongside the overall greater complexity of SuperPON systems means that reliable software is important. However, to estimate the impact of software failure on the SuperPON is a complex task made the more difficult by the lack of hard failure data (though the microprocessor reset times for the various PLANET modules are, of course, well known). The options for redundancy in software are different to those in hardware, since it is futile duplicating programs with the same bugs. The MDT figures produced in preliminary studies suggested that it was unlikely that advanced techniques, such as multiple versions of the software, will be required if software failures occur infrequently (less than once a week). Software failure is viewed as negligible in the MDT calculations later in this paper.

Requirement R2) necessitates ONUs that support telephony to have battery back-up. Whether ONUs not supporting telephony have battery back up depends on the operator's policy. The local powering concept is used for PLANET, assumed here to have an availability of $99.999 \%$ [14]. This figure takes into account that, as well as a connection to the public energy supply, all powered nodes have battery, or (at more important points) diesel or gas turbine generator, backup. Requirement R3) directly relates to the need for rapid protection switching mechanisms. Requirement R4) [and R3] can be related to major incidents, like the destruction of an AN. As such incidents are rare, they don't affect the calculated network availability. However, if such an event did occur, the repair of a totally destroyed AN could take several months. For the user it is unacceptable to be out-of-service for so long [R3], for the operator it is not good to risk dissatisfaction of many users (and revenue loss) by one incident [R4]. Such risks to the network survivability can be reduced by a special form of redundancy know as dual homing (see Section V).

\section{OPTIONS FOR REDUNDANCY}

Since an unprotected SuperPON cannot easily meet even the relatively relaxed MDT requirement of multimedia services, the availability of the network must be improved by implementing physical layer redundancy in the form of protection elements (optical amplifiers, OLTs) and double routed fiber cables. When a failure occurs rapid protection switching (typically within 50 $\mathrm{ms}$ ) is required in order to bring the spare into operation in the main path, whilst removing the original from the main path. There are a number of different options for redundancy. The internodal redundancy options are shown in Fig. 3, with various 


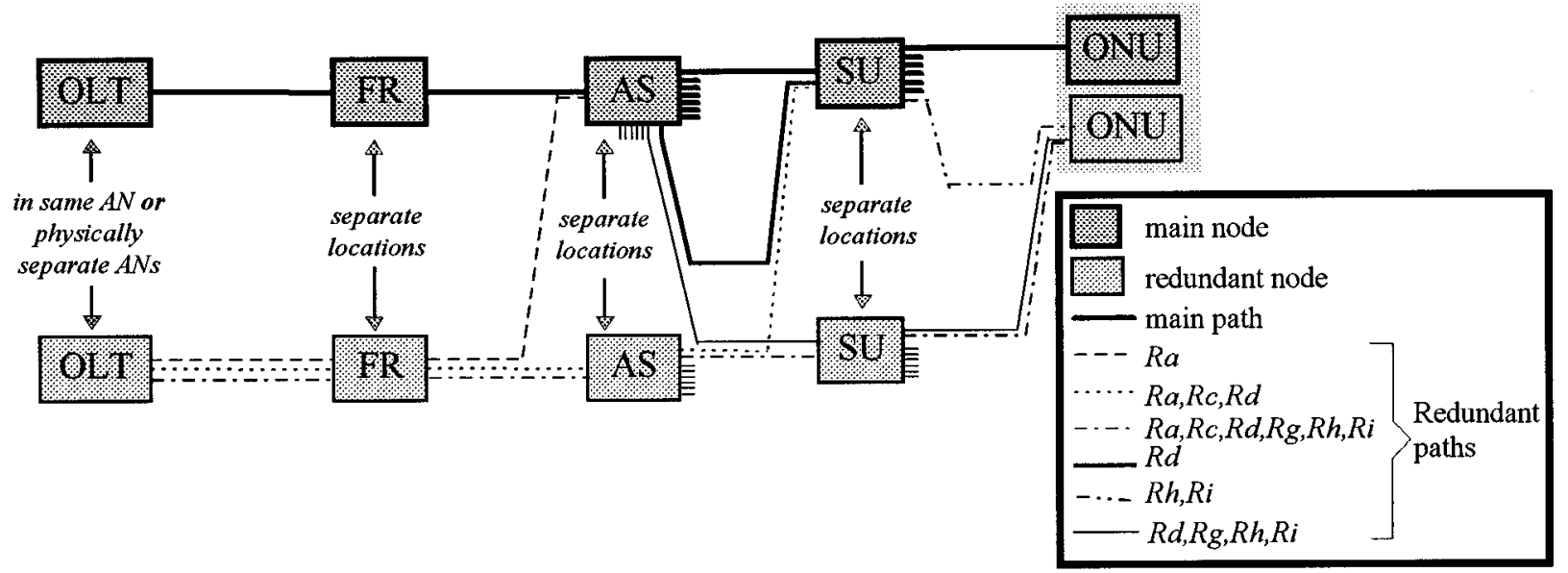

Fig. 3. Redundant internodal SuperPON topologies.

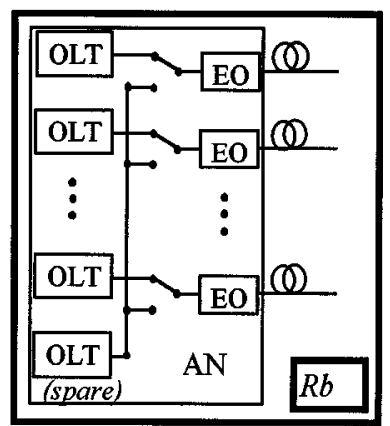

(a)
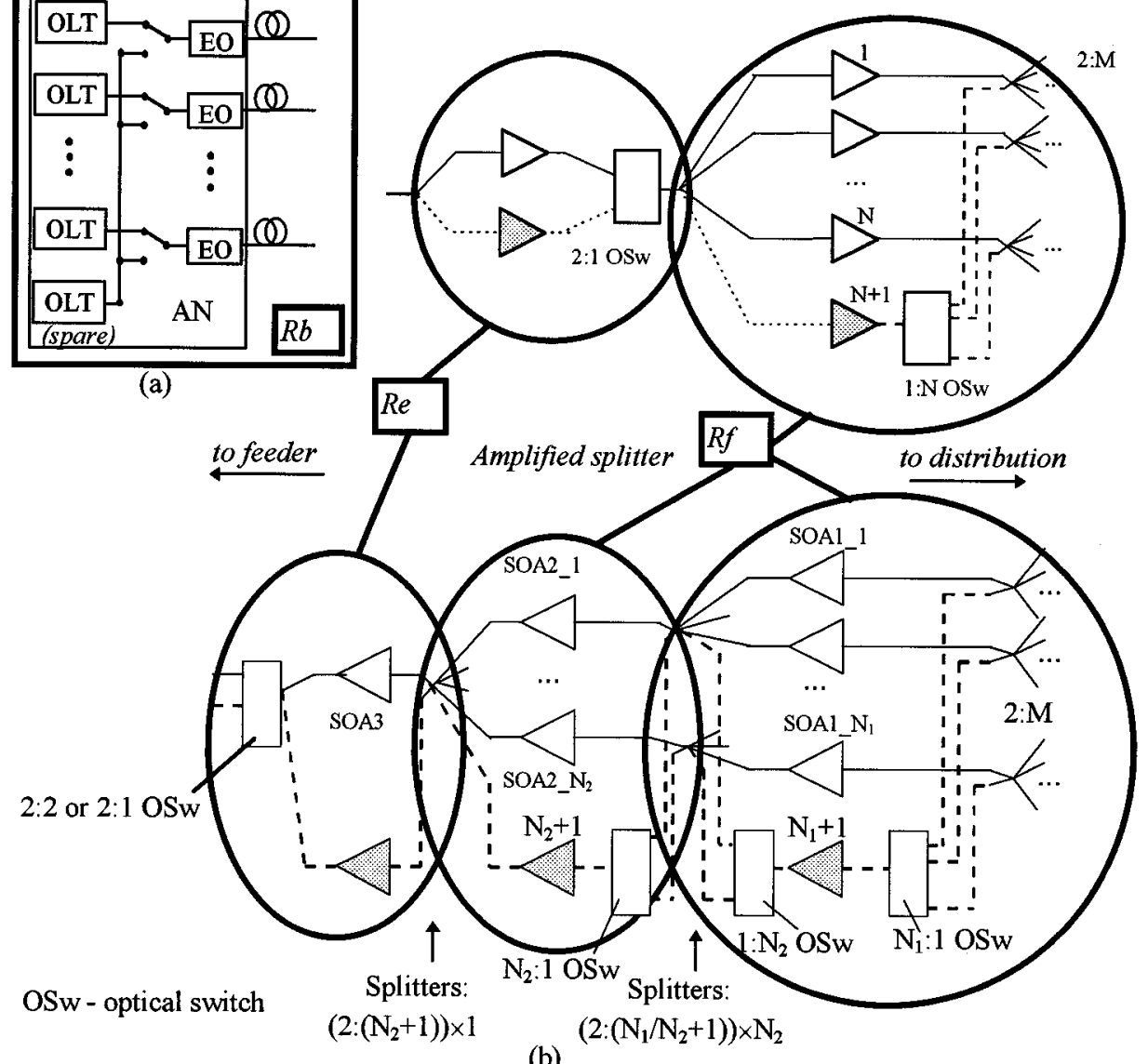

(b)

Fig. 4. Intranodal redundancy options. (a) $N+1$ protection of the OLTs of different SuperPON systems homed at the same AN. (b) The upper portion shows $N+1$ protection of downstream EDFAs in the AS while the lower portion shows $N+1$ protection of upstream SOAs [specifically first stage (SOA1) and second stage (SOA2)]. $1+1$ protection is shown for the amplifiers in the common path in both the upstream and downstream. Note that the combination of the main and redundant paths on the distribution, here depicted conceptually as a $2: M$ splitter, will actually involve $1300 \mathrm{~nm} / 1550 \mathrm{~nm}$ WDMs and optical switches (due to the optical switching needs of D1 protection and as D1 consists of single bidirectional fiber).

combinations of the different options making up the set of possible redundant paths. The intranodal redundancy options are depicted in Fig. 4. Fig. 4(a) shows $N+1$ protection of the OLTs of different SuperPON systems homed at the same AN, facilitated by the placing of the optoelectronic components (Tx/Rx) on a separate EO board. The upper portion of Fig. 4(b) shows $N+1$ protection of downstream EDFAs in the AS (typically
$N=16$ ), while the EDFA in the common path is protected with a dedicated spare. The lower portion of Fig. 4(b) shows $N+1$ protection of upstream SOAs in the AS. Typically there are $N_{1}=32$ first stage SOAs (SOA1s), plus one spare, and $N_{2}=4$ second stage SOAs (SOA2s), plus one spare. The third stage SOA (SOA3) in the common path, is protected with a dedicated spare. In Table II, further description of each redundancy 
TABLE II

REDUNDANCY OPTIONS FOR FTTH SUPERPON

\begin{tabular}{|c|c|c|}
\hline Protection & Implementation description & Normal redundancy requirement? \\
\hline $\begin{array}{l}R a) \quad \text { Double } \\
\text { routed (i.e. path } \\
\text { diverse) feeder } \\
\text { (Figure 3) }\end{array}$ & $\begin{array}{l}\text { At the AS optical switches switch between feeders or alternatively } \\
\text { passive splitters combine them. The feeders arise in two ways:- } \\
\text { 1) a redundant sub-board at the OLT, containing a redundant laser } \\
\text { transmitter and burst mode receiver, to terminate the redundant feeder } \\
\text { 2) a second OLT in a physically separate access node (AN) to which } \\
\text { the second feeder attaches (i.e. dual homing - see Section V). }\end{array}$ & $\begin{array}{l}\text { Yes (essential), as an unprotected } \\
\text { feeder (nominally } 90 \mathrm{~km} \text { long) is the } \\
\text { most vulnerable SuperPON part } \\
\text { failure (e.g. cable cut) will cause loss } \\
\text { of service to all users for several hours. }\end{array}$ \\
\hline $\begin{array}{l}\text { Rb) } \mathrm{N}+1 \text { optical } \\
\text { line termination } \\
\text { (OLT) protection } \\
\text { (Figure 4) }\end{array}$ & $\begin{array}{l}\text { OLTs of } N \text { individual SuperPON systems housed in the same AN } \\
\text { share a spare OLT, also in the same AN, in case of OLT failure. }\end{array}$ & $\begin{array}{l}\text { No, has little impact on MDT as OLT } \\
\text { failures rare relative to feeder failures } \\
\text { \& both protected by fast switchover to } \\
\text { the redundant OLT in the other AN. }\end{array}$ \\
\hline $\begin{array}{l}\text { Rc) Duplicated } \\
\text { amplified splitter } \\
\text { (AS) (Figure 3) }\end{array}$ & $\begin{array}{l}\text { As the feeder and DI are to be double routed as standard it is possible } \\
\text { to also duplicate the AS by placing the second a significant distance } \\
\text { away (up to } 2 \mathrm{~km} \text { ), primarily to enable its survivability of catastrophic } \\
\text { incidents. }\end{array}$ & $\begin{array}{l}\text { No, as it leads to a large cost increase } \\
\text { per user for FTTH'. Also the system } \\
\text { could only reach users in the overlap of } \\
\text { each AS's range. }^{2} \text {. }\end{array}$ \\
\hline 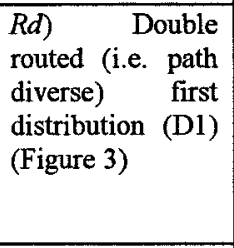 & $\begin{array}{l}\text { Either requires a duplicated AS (see above) or optical switches on the } \\
\text { distribution side of the AS toggle between the main fibre and the } \\
\text { spare, which is attached to the SU on the second input port of a } \\
\text { standard splitter ( } 2: \mathrm{N} \text { instead of } 1: \mathrm{N} \text { ). Then, assuming a roughly } \\
\text { rectangular grid the two fibre lengths will not differ enough to } \\
\text { seriously affect the power budget (unlike when the AS is duplicated) } \\
\text { but enough to require a ranging of the redundant path (see Section VI) }\end{array}$ & $\begin{array}{l}\text { Yes, as cable failure in the first } \\
\text { distribution section generally becomes } \\
\text { the dominant unavailability } \\
\text { contribution if the feeder is protected. }\end{array}$ \\
\hline $\begin{array}{l}\text { Re) Intra-node } \\
\text { optical amplifier } \\
\text { (OA) protection: } \\
1+1 \text { (Figure 4) }\end{array}$ & $\begin{array}{l}\text { Such protection (in the feeder repeater (FR), and for the OAs in the } \\
\text { common (not branched) AS section) is implemented using a passive } \\
\text { splitter at the input end and an optical switch at the output. This } \\
\text { scheme has the advantages that the output of the failed device can be } \\
\text { terminated away from the main path, the spare SOA or EDFA can be } \\
\text { kept powered up in a permanent state of readiness and its functioning } \\
\text { can be monitored while being exposed to a live signal. These } \\
\text { advantages are not all obtainable if either passive splitters or optical } \\
\text { switches are used at both ends. }\end{array}$ & $\begin{array}{l}\text { Yes (for OAs in the common section of } \\
\text { the AS) as unprotected they constitute } \\
\text { a single point of failure. } \\
\text { No (for the FR), as the availability } \\
\text { improvement from protecting the FR } \\
\text { OAs is negligible when the feeder is } \\
\text { double routed - a rapid switching } \\
\text { mechanism between feeders must } \\
\text { already exist. }\end{array}$ \\
\hline $\begin{array}{l}R f \text { Intra-node } \\
\text { optical amplifer } \\
\text { protection: } \mathrm{N}+1 \\
\text { (Figure 4) }\end{array}$ & $\begin{array}{l}N \text { parallel optical amplifiers on different branches within the AS site } \\
\text { share one spare. The optical switch ONU side of the redundant optical } \\
\text { amplifier adds about } 1 \mathrm{~dB} \text { to the distribution section attenuation. As } \\
\text { there are two parallel amplifier stages upstream, other upstream } \\
\text { arrangements exist, changing the redundant path routing through } \\
\text { different splitting and optical switching configurations. }\end{array}$ & $\begin{array}{l}\text { Yes, as this is an extremely cost- } \\
\text { effective method of significantly } \\
\text { reducing the MDT of the AS. }\end{array}$ \\
\hline $\begin{array}{l}\text { Rg) Splitter unit } \\
\text { (SU) duplicated } \\
\text { (Figure 3) } \\
\end{array}$ & $\begin{array}{l}\text { Only useful when whole distribution network (D1 and D2) is double } \\
\text { routed (intra-nodal duplication of the splitter is evidently futile) }\end{array}$ & $\begin{array}{l}\text { No, since } \mathrm{D} 2 \text { is not generally double } \\
\text { routed accross the whole network. }\end{array}$ \\
\hline $\begin{array}{l}R h \text { ) Double } \\
\text { routed (i.e. path } \\
\text { diverse) second } \\
\text { distribution (D2) } \\
\text { (Figure 3) }\end{array}$ & $\begin{array}{l}\text { A second D2 fibre from the same SU is routed to the ONU (or } \\
\text { redundant ONU, which may be more straightforward due to the cost of } \\
\text { optical switching or of modifying the ONU to have two O/E fibre } \\
\text { interfaces). Each D2 fibre used for protection in this way reduces the } \\
\text { total number of users that the SuperPON can serve (increasing the SU } \\
\text { splitter ratio is not possible for power budget reasons), thus the } \\
\text { operator will need to levy a substantially higher charge. } \\
\text { D2 can also be duplicated from a separate SU when the whole } \\
\text { distribution network is to be duplicated. }\end{array}$ & $\begin{array}{l}\text { No, on cost grounds, though double } \\
\text { routing D2 may be considered for cases } \\
\text { of individual users (or groups, if } \\
\text { FTTC) requiring better availability }{ }^{4} \text {, } \\
\text { but makes more sense in conjunction } \\
\text { with ONU duplication }\end{array}$ \\
\hline $\begin{array}{lr}R i) & \text { Redundant } \\
\text { optical } & \text { network } \\
\text { unit } & (\mathrm{ONU}) \\
\text { (Figure 3) } & \end{array}$ & $\begin{array}{l}\text { Straightforward when D2 double routed but, when it is not, duplicate } \\
\text { the ONU components within a single, super-reliable, ONU. } \\
\text { (Otherwise, using a passive } 3 \mathrm{~dB} \text { coupler to attach two ONUs to the } \\
\text { same D2 fibre has poor power budget whilst local control \& powering } \\
\text { of optical switching between two ONUs is costly \& complex) }\end{array}$ & $\begin{array}{l}\text { No, on cost grounds, though ONU } \\
\text { redundancy may be considered for } \\
\text { individual users requiring better } \\
\text { availability, but makes more sense in } \\
\text { conjunction with D2 duplication }\end{array}$ \\
\hline
\end{tabular}

$\underline{\text { Notes }}$

1. It is largely equivalent to duplicating the local office in the current telephony network, which network operators prefer to avoid.

2. This is because the distribution section is the power budget bottleneck [2] and some SUs (and thus ONUs) will require much longer fiber spans to one AS than to the other.

3. As $N$, in the unprotected SuperPON, is a power of 2 providing an $N+1$ way split requires nonstandard components-typically a 1:17 splitter in the downstream and one 2:5 and four 2:9 splitters in the upstream. If this proved problematic, the precise number of ONUs served by the system could be adjusted so that $N+1, N_{1} / N_{2}+1$, and $N_{2}+1$ are all standard splitting ratios; however, care must be taken to match the total upstream and downstream splits.

4. It is possible to duplicate the $\mathrm{SU}$ and thus double route the whole distribution section, which constitutes a massive additional cable and civil works cost that could only be considered when D2 duplication is required for the majority of users. 


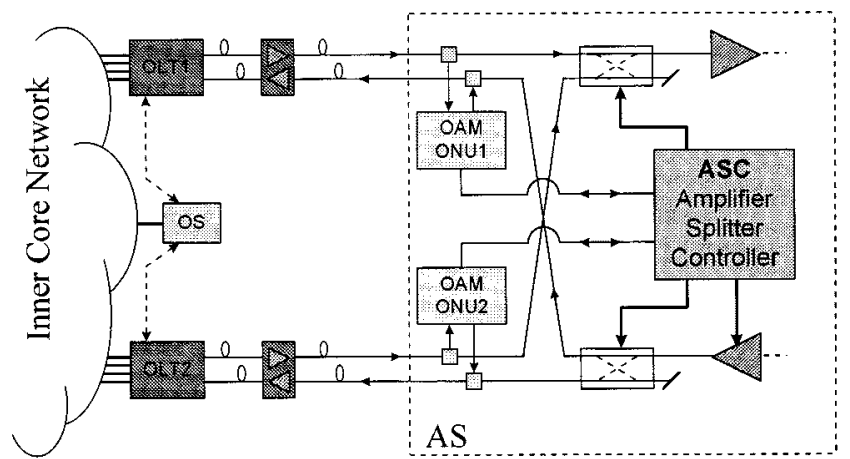

Fig. 5. Single AS solution using optical switches.

option $(R a-R i)$ is provided, along with whether they are regarded as a normal redundancy requirement and why, with an orientation toward FTTH. For FTTC, it should be noted that duplication of the VDSL NT is also potentially appropriate, if required. However, it is not appropriate for the copper cable length between the FTTC ONU and the NT to be duplicated, as this violates the operator's intention to only re-use the copper that is presently available in the network.

From the considerations in Table II, which are partly informed by the availability versus cost results of Section VII, it is apparent that the normal redundancy requirement for a FTTH SuperPON consists of a double routed feeder, a double routed first distribution section and protection $(N+1$ for parallel OAs, $1+1$ for OAs at the feeder-AS interface) of the OAs in the amplified splitter. Other possibilities, such as double routing D2 or duplicating the ONU, can be considered for those customers with more stringent availability requirements.

\section{DuAl Homing SuPERPON SySTEMS}

In this section, two different approaches, the single and distributed amplified splitter solutions, to dual homing SuperPON systems are described, compared, and contrasted. Dual homing is essentially the connection of ONUs to two ANs, and thus two core network switches, in an attempt to improve the network's resilience to a localized catastrophic failure at an AN. The single amplified splitter solution arises quite naturally from the fact that the feeder is double routed as part of the normal redundancy requirement. A double amplified splitter solution, countering the network vulnerability to catastrophe at the AS, is not considered for the reasons stated in Table II. However, a distributed amplified splitter solution, with the advantage of (partial) network survivability to incidents at the AS, as well as double capacity and applicability to low user density areas, is a strong candidate.

\section{A. Dual Homed Single Amplified Splitter (DH-SAS) Solution}

In Fig. 5, a dual homed single amplified splitter is depicted (and hence this solution does not provide protection from a catastrophic accident affecting the AS location). Here, all traffic is supported by a single OLT, whilst the other is used only in case of failure of the main path. The backup OLT is, however, active and it communicates with the related operation, administration and maintenance (OAM) ONU to continuously monitor the protection path. Note that OAM-ONUs are also present

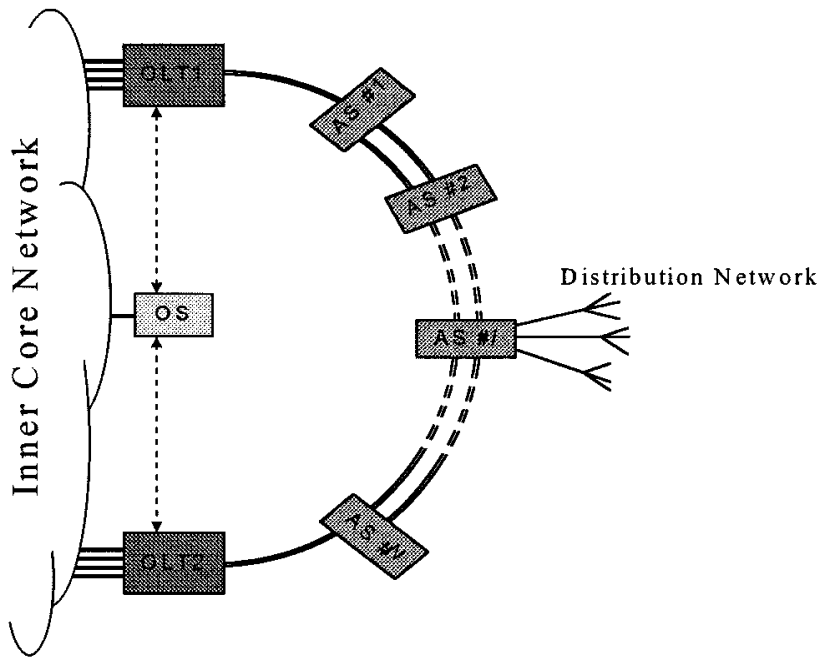

Fig. 6. Distributed amplified splitter architecture principle.

at the FRs, but in this paper, except where stated otherwise, OAM-ONU will refer to those based at the AS. Two paths to the AS are available from two different locations, far apart from each other: in the AS, crossover optical switches, controlled by a switchover controller (SOC) within the amplified splitter controller (ASC), are used to select the working path. Notice that the OAM-ONU is duplicated to allow monitoring of the protection path, as the standby OLT(2) establishes a point to point communication with the standby OAM-ONU(2). The active OAM-ONU(1) is the means by which the ASC can exchange OAM information with OLT1 and the operation system (OS). It also passes to the ASC the synchronization information needed to switch on/off the burst mode SOAs. The OAM information channel from the ASC to OLT1 and OS can be duplicated via the OAM-ONU2 which, as noted above, maintains continuous communication with OLT2. Thus, control of the AS from the OS can be maintained also in case of a main path fault. In case of fault in any element of the main path, the OAM-ONU detects a loss of signal (or just a performance degradation) and informs the ASC; after a pre-defined period of time the ASC orders the optical switches to exchange the optical paths, and informs (via the protection path) the OS that protection switching had to be performed. From this moment on, the management OS knows that a serious impairment has occurred on the main path and hence that traffic needs to be restored via the protection path. Note that re-routing of ATM traffic from/to the main AN to the protection AN may imply re-establishment of all active connections, involving the resources of the inner-core network.

\section{B. Dual Homed Distributed Amplified Splitter (DH-DAS) Solution}

Given that, in low user density areas, the SuperPON capacity would be inefficiently used, and also that in the DH-SAS the bandwidth capacity of the OLT (and the switches) in the redundant central office is not used efficiently, a SuperPON with a distributed drop topology is identified. Since long feeders using cascades of up to $16 \mathrm{SOA}$ are feasible [2], it is possible to have several dropzones connected to one SuperPON feeder. Thus, in the DH-DAS architecture (see Fig. 6), several AS locations exist, and from each AS a distribution network originates. The 


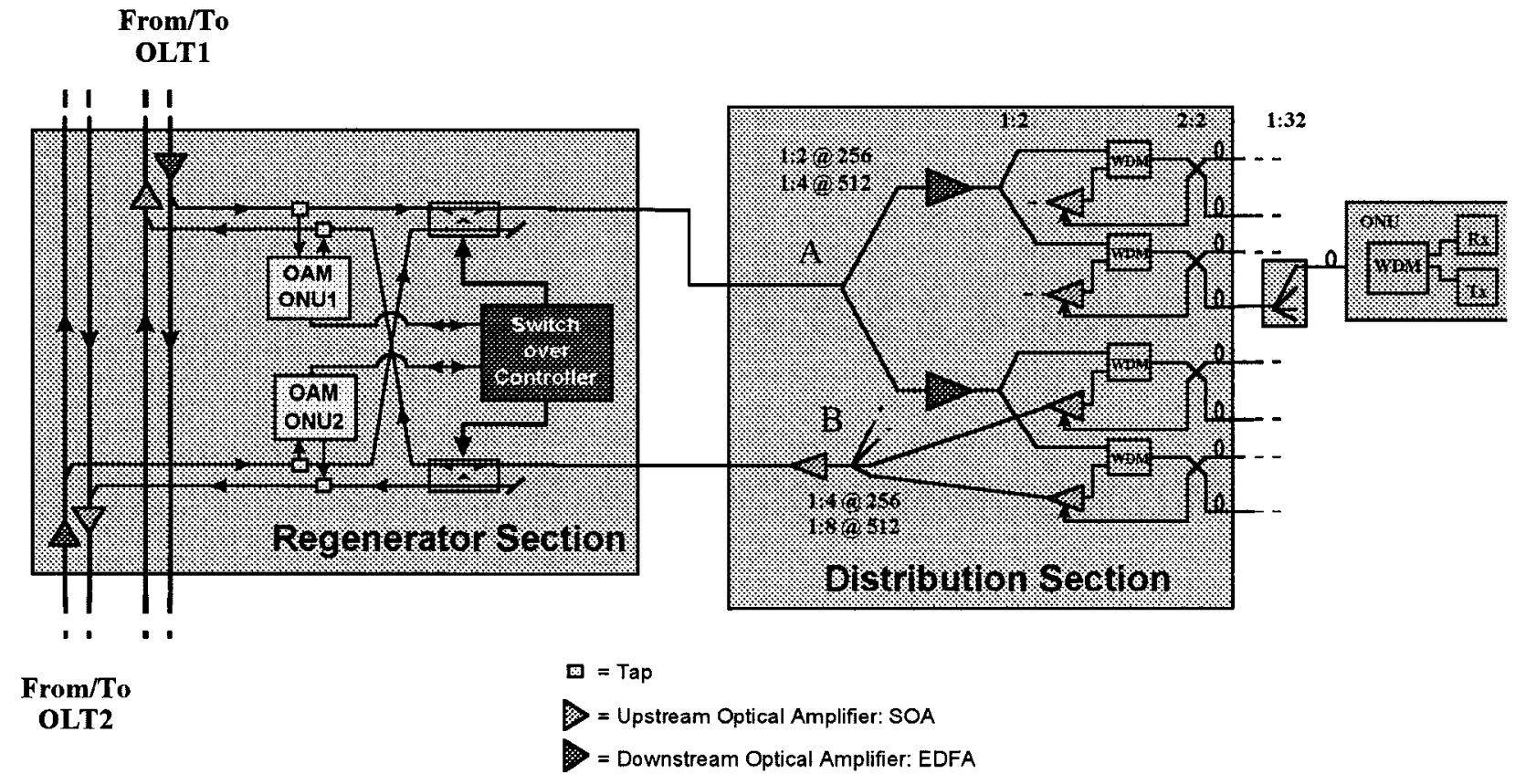

Fig. 7. Amplified splitter for the DH-DAS architecture.

bandwidth share may be flexibly modified to adapt to the needs of a new neighborhood or a new business user. Upon cable cut in the feeder ring, some of the drop zones are switched over. The number of ONUs ordinarily served by one OLT here should be smaller than 2048, so that one AN can take over the complete SuperPON in case of, for example, a catastrophic failure in the other AN. Since more users will be connected to one OLT upon switchover, it may be necessary to reduce the bandwidth of connections with a lower grade of service to cope with the smaller average bandwidth available per user. To map this architecture on to the existing duct infrastructure, the number of users served by each AS should be close to the number of users served by existing cabinets (several hundreds). Thus, it is likely that there are either 256 or 512 users per AS, with, respectively, eight or four ASs to support 2048 ONUs. The AS for the DH-DAS architecture is shown in Fig. 7 and incorporates a "regenerator section" for amplification in the feeder ring, and to manage switchover on the ring between the two OLTs, and a "distribution section" for amplification and splitting of the signal to/from the distribution network. While the distribution section changes depending on whether 256 or 512 users are served by the AS, the regenerator section is unchanged. OAM-ONUs are present on each path between the AS and each OLT in order to monitor the downstream signal, extract/insert OAM information to/from the AS, and provide the SOC with the necessary information for protection switching. The distribution section is designed with a structure similar to the original one; in fact the only modification needed is to adjust the splitting ratio at reference points (A) and (B) in Fig. 7 depending on the number of attached ONUs.

\section{Comparison of the Two Dual Homing Techniques}

Table III summarizes and compares the main characteristics of the single AS and distributed AS solutions.

It may be noted from Table III that the DH-DAS solution is preferable over the DH-SAS solution in terms of bandwidth capacity and network protection capacity (in the event of either a feeder fiber or AS failure). That is, double bandwidth capacity is available in normal operation and no single major incident at any network element is able to completely interrupt traffic on the entire network. It should be noted that any distinction between the two approaches in terms of cost will be based on the fact that the DH-DAS solution requires the provision and maintenance of a greater number of amplified splitter cabinets per user (though the amount of optical equipment per user is virtually identical).

\section{Protection Mechanisms}

In this section protection switching issues are discussed, and protection time calculations are performed, for a DH-SAS architecture, augmented by redundant optical amplifiers in the AS and double routed D1 fibers (the normal redundancy requirement). However, first some further remarks about the SuperPON system are appropriate. First, it should be noted that the transport system uses physical layer OAM (PLOAM) cells for conveying messages between the micro-controllers of different locations. In a deployed PLANET system there will be one software platform and transmissions via a common bus, leaving a single microprocessor (plus spare) at the AS. The SOC and the burst mode operation of SOA control function are duplicated, and integrated within each OAM-ONU. Thus, if the OAM-ONU fails its entire integrated functionality is switched to the spare OAM-ONU, with a feeder change. The OAM-ONU is also assumed to be capable of a transmission power level comparable with the upstream signal leaving the AS (just amplified by SOA3), which is not possible with the standard PLANET ONU transmitter but an additional dedicated SOA may be used without significant cost or MDT increases. There are optical monitoring points at the output of each SOA and at both the input and output of each EDFA. At all these places, and also the OLT and the OAM-ONUs at the AS (and FR), it may be necessary for the OA failure/loss of signal to be recognized rapidly, initiating a train of events leading to a protection action. 
TABLE III

COMPaRISON RFTWFFn DH-SAS aND DH-DAS SOI ITIONS

\begin{tabular}{l||c|c|c||c|c|c}
\multicolumn{1}{c||}{} & \multicolumn{3}{c||}{ Single AS } & \multicolumn{3}{c}{ Distributed AS (N= number of ASs) } \\
\cline { 2 - 7 } & $\begin{array}{c}\text { BW } \\
\text { capacity } \\
{[\%]}\end{array}$ & $\begin{array}{c}\text { BW } \\
\text { distribution } \\
\text { between } \\
\text { OLTs }^{2}[\%]\end{array}$ & $\begin{array}{c}\text { Network } \\
\text { protection } \\
\text { capability }\end{array}$ & $\begin{array}{c}\text { BW } \\
\text { capacity } \\
{[\%]}\end{array}$ & $\begin{array}{c}\text { BW } \\
\text { distribution } \\
\text { between } \\
\text { OLTs }^{2}[\%]\end{array}$ & $\begin{array}{c}\text { Network protection } \\
\text { capability }^{3}\end{array}$ \\
\hline Normal Operation & 100 & $100 / 0$ & not applic. & 200 & $100 / 100$ & not applic. \\
\hline OLT fault & 100 & $0 / 100$ & $100 \%$ & 100 & $100 / 0$ & $50 \%{ }^{4}$ \\
\hline Feeder fibre fault & 100 & $0 / 100$ & $100 \%$ & 200 & $100 / 100$ & $P$ where $50 \leq P \leq 100 \%^{4}$ \\
\hline FR fault & 100 & $0 / 100$ & $100 \%$ & not applic. & not applic & not applic. \\
\hline AS fault & 0 & $0 / 0$ & 0 & 200 & $100 / 100$ & $\frac{N-1}{N} \cdot(P \%)^{5}$ \\
\hline
\end{tabular}

Notes

1. Total usable bandwidth capacity of both OLT1 and OLT2 as a percentage of an unprotected PLANET system bandwidth capacity ( $2.5 \mathrm{Gbit} / \mathrm{s}$ downstream $-311 \mathrm{Mbit} / \mathrm{s}$ upstream).

2. Usable bandwidth capacity distribution between OLT1 and OLT2 (OLT1/OLT2) as a percentage of an unprotected PLANET system bandwidth capacity $(2.5 \mathrm{Gbit} / \mathrm{s}$ downstream - $311 \mathrm{Mbit} / \mathrm{s}$ upstream).

3. Percentage of the impaired traffic that can be restored with a protection switching action compared to the normal operation bandwidth capacity.

4. The normal operation bandwidth capacity for this case is $200 \%$.

5. Assuming a uniform traffic distribution among ASs.

Redundancy has a major impact on the system start up since, to reduce traffic interruption time when protection switching, ranging, gain leveling and burst mode receiver setting are also carried out for the redundant paths. Thus, the initialization time will be longer in a protected architecture. Once the system is operational, regular monitoring of the redundant components and paths will be required, so that they are available if needed. Monitoring to verify availability of the redundant feeder is easily performed as its OAs must be continually on for fast protection (two way communication is provided between the redundant OLT and the redundant OAM-ONU and this path is shut off from the live paths by optical switches at the AS). To verify availability of the spare OAs note that the redundant EDFAs are always on, and exposed to the downstream signal, enabling continual input and output monitoring, while monitoring the redundant burst mode SOAs is effected by switching them on and off during idle time slots (not necessary for the redundant SOA3 as its output can be terminated away from the main path).

As well as monitoring for availability, it will be necessary to monitor the optical power levels for the redundant paths, since releveling at the time of protection switching is too time consuming (it would have to be done individually for each affected ONU through the new path). The gain of burst mode SOAs are set differently for each ONU to limit the necessary dynamic range of the OLT burst mode receiver. These levels, and those for the burst mode receiver itself, need to be set for the redundant paths through the burst mode SOAs at system start up and then periodically checked/releveled (due to temperature or stress induced polarization changes or wavelength fluctuations), for each ONUs path through each redundant SOA. This can be carried out by checking during idle slots, and, if necessary, a full releveling can then be commanded. It is facilitated because the optical switching is only in the redundant path, so the redundant path selection can be made without traffic interruption.
Ranging is a particularly important consideration since the round-trip delay (RTD) will change upon switchover, even of optical amplifiers (due to different patch-cord lengths). Thus, affected ONUs need to be assigned new ranges for correct operation of the TDMA mechanism. Rearranging of all affected ONUs is time consuming and slows down the switchover time, so the RTD of the possible redundant paths are ranged during initialization of the system or connection of a new ONU. In many cases it will be sufficient to range the redundant path for one ONU and to calculate the RTD for the other ONUs affected by a specific switchover, followed by a verification. The equalization delays for the various protection scenarios are locally stored at the ONU, and activated by a broadcast message from the OLT upon switchover. The RTD of the redundant paths will, however, vary during operation due to temperature variations. Small changes up to one bit in duration can be handled in hardware. To accommodate larger time shifts, the range of the redundant paths should be monitored and updated frequently during operation. There is generally no need for a controlled traffic interruption to facilitate this since the range can be updated at the same time that ordinary ranging for an ONU over the live path is performed, by applying the same change in the "live" range of the ONU to the ranges of the redundant paths involving that ONU. This approach can be applied to any protection path that is not different to the main path in its fiber sections. Protections involving D1 or the redundant feeder require more care, but these redundant paths can also have their range kept up to date with only a minimal recourse to re-ranging with traffic interruption. For example re-ranging is potentially unnecessary even when switching feeders. To facilitate this it is noted that the range of OAM-ONU1, and thus the live feeder, is continually updated at OLT1. Similarly the range of OAM-ONU2, and thus the redundant feeder, is continually updated at the redundant OLT2. Then, the range of paths from OLT2 to customer ONUs through 
TABLE IV

PROTECTION TIMES FOR REDUNDANT PARTS

\begin{tabular}{l|l|l}
\hline \multicolumn{1}{c|}{$\begin{array}{c}\text { Protected } \\
\text { network part }\end{array}$} & \multicolumn{1}{|c}{ Condition to protect within $50 \mathrm{~ms}$} & \multicolumn{1}{c}{ Comments } \\
\hline EDFAs in AS & $t_{1} \leq 21.55 \mathrm{~ms}^{1}$ & $\begin{array}{l}t_{1} \text { is the (programmable) interval between PLOAM cells } \\
\text { for OAM-ONU1 }\end{array}$ \\
\hline SOA3 & $\begin{array}{l}t_{2}+t_{1} \leq 22.45 \mathrm{~ms} \text { (module) \& } t_{1} \leq 22.3 \mathrm{~ms} \text { (control } \\
\text { electronics) }\end{array}$ & $\begin{array}{l}t_{2} \text { is the (programmable) interval between dark cells for } \\
\text { the whole network. If } t_{2}>0.15 \mathrm{~ms} \text { the SOA module } \\
\text { takes the longest to protect }{ }^{2}\end{array}$ \\
\hline SOA2 & $\begin{array}{l}t_{3}+t_{1} \leq 22.45 \mathrm{~ms} \text { (module) \& } t_{1} \leq 22.3 \mathrm{~ms} \text { (control } \\
\text { electronics) }\end{array}$ & $\begin{array}{l}t_{3}=4 t_{2} \text { is the interval between programmed dark cells } \\
\text { on the SOA2 branch. If } t_{2}>0.15 / 4 \text { ms the SOA module } \\
\text { takes the longest to protect }\end{array}$ \\
\hline SOA1 & $\begin{array}{l}t_{4}+t_{1} \leq 22.45 \mathrm{~ms} \text { (module) \& } t_{1} \leq 22.3 \mathrm{~ms} \mathrm{(control} \\
\text { electronics) }\end{array}$ & $\begin{array}{l}t_{4}=32 t_{2} \text { is the interval between programmed dark cells } \\
\text { on the SOA1 branch. If } t_{2}>0.15 / 32 \text { ms the SOA module } \\
\text { takes the longest to protect }\end{array}$ \\
\hline D1 & $t_{5}+t_{1} \leq 22.45 \mathrm{~ms}^{1,3}$ & $\begin{array}{l}t_{5}=t_{4}+(x-1) t_{b P L O A M i n t} \& t_{b r P L O A M i n t} \text { is the interval } \\
\text { between PLOAMs on the whole D1 (SOA1) branch }\end{array}$ \\
\hline Notes & &
\end{tabular}

Notes

1. Up to $10 \mathrm{~ms}$ may be saved by using faster optical switches.

2. Due to a longer detection time incorporating the need to monitor a dark cell for ASE.

3. For example the total system PLOAM rate is typically around 1 in every 32 cells ( 22 per ms), thus $t_{b r P L O A M i n t}=32 \times$ $32 \times 1.44 \mu \mathrm{s}=1.5 \mathrm{~ms}$ (where $1.44 \mu \mathrm{s}$ is the upstream ATM cell duration with a 3 byte MAC field) and the target attained with $t_{1}=5 \mathrm{~ms}, x=3$ and $t_{2}=t_{4} / 32=0.25 \mathrm{~ms}$ (i.e. system dark cell rate $=4$ per ms) and $6.45 \mathrm{~ms}$ spare.

the redundant feeder, can simply be obtained by adjusting the ranges from OLT1 before the failure with the difference in the ranges OLT1 to OAM-ONU1 and OLT2 to OAM-ONU2. This can be done at OLT2, by virtue of it receiving OLT1s up to date ranging information via a core network connection.

The OLT monitors system performance by registering upstream PLOAM cells periodically sent by each ONU. If some PLOAM cells do not arrive, the OLT can deduce which part of the network is involved in a failure and stop giving permits for upstream traffic from affected ONUs. In the case of an OA failure and the path between the corresponding OAM-ONU and the OLT remaining available, the OLT is informed about the cause of the failure. In the other case the reason may be a cable cut or an OA failure in a local node further downstream. In that case the OLT first waits before commencing switch-over to the redundant OLT, to see whether there is indeed a local node failure which it is possible to restore within $50 \mathrm{~ms}$. Such fast switchover is feasible since the ranging and leveling of the redundant paths are carried out in advance, and frequently updated, as described above. It should be noted that if ONUs each send PLOAM cells periodically at a sensible rate that is bandwidth inexpensive (e.g., every 1 out of 32 cells so that each ONU sends a PLOAM cell every $90 \mathrm{~ms}$ ) the system must be programmed so that OAM-ONUs use a different, higher rate (e.g., a PLOAM every 5-10 ms) otherwise they can play no part in the recovery process after a failure (that process must be complete within $50 \mathrm{~ms}$ ). If the problem is found to be in the common feeder/OLT part of the network, then protocol control switchover (PCS) is instigated (i.e., control of the MAC etc. is handed from OLT1 to OLT2). The redundant OLT becomes aware that it must "go live" either via the core network (any direct communication, including the exchange of ranging information, between the two OLTs occurs in the core network) or via the OAM-ONUs in the AS. PCS occurs in differing failure circumstances, with differing protection times (all around $50 \mathrm{~ms}$ ) due to different detection times and differences in the extent to which information is known at each of the two OLTs and the two OAM-ONUs. However $50 \mathrm{~ms}$ is not necessarily the time to reconnection, since the core network also has to perform significant re-routing, beyond the present scope. These times compare favorably with those for the APON [9] because here a mechanism is assumed whereby ranging for the new OLT-ONU links has been carried out in advance, via regular communication of ranging information from OLT1 to OLT2 before switchover, as described earlier.

The procedures for the protection of the various network elements [i.e., for it to be possible for live communication between the OLT and affected ONU(s) to be re-established] are too lengthy to detail here. The timings of the procedures, given here, were obtained from a detailed consideration of the order of events, and the state of the system after each, given many known time durations (e.g., optical switching time, propagation times, cell processing and assembly times, RTD including timing equalization at the ONU, etc.) and programmable time intervals (see below). It is assumed, for simplicity, that there is a single failure originating event. Note also that there are different ways for an optical amplifier to fail and thus different detection and protection times. The EDFA or SOA module could itself fail, but control electronics failure is more likely. The timings given below account for the longest of these processes. For D1 protection the SOC in the AS realizes that the absence of signals is due to a D1 failure if there is a continuous loss of PLOAM cells (at SOA1 output) from $x>1$ ONUs on that SOA1 branch without loss of ASE (the larger $x$ the longer the detection time, but the surer it is that D1 has failed rather than independent events disconnecting several, but not all, ONUs on that branch). An optical switching time of $15 \mathrm{~ms}$ was assumed, but switching times as low as $5 \mathrm{~ms}$ are feasible. The protection time results are summarized in Table IV. Note that $t_{1}$ is the (programmable) interval between PLOAM cells specifically for 


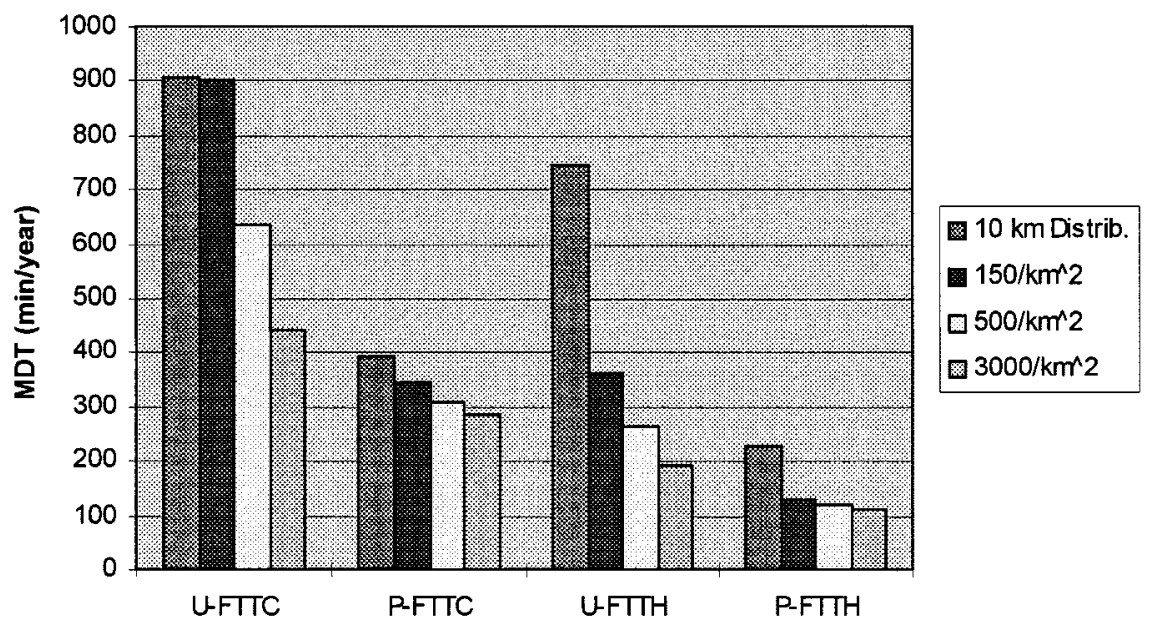

Fig. 8. MDT of various architectures $(\mathrm{min} / \mathrm{y})$ using conservative MTTR and fiber failure rates $(\mathrm{U}=$ unprotected apart from redundant feeder, $\mathrm{P}=$ protected with normal redundancy requirement).

the OAM-ONU1 and $t_{2}$ is the (programmable) interval between dark cells for the whole network. Programmed dark cells occur as a result of an unused grant (as opposed to those arising from a lack of traffic) and can be used to monitor SOA ASE levels, thus giving an indication of correct SOA functioning in a periodic fashion for each branch of the upstream network. It can be seen, from Table IV, that the principle of protection switching within $50 \mathrm{~ms}$ is feasible for a SOA based SuperPON. Similar to a conventional APON, if POTS (plain old telephony service) or ISDN are considered then a "hitless" protection switching can be achieved since these connections remain open if the link is not down for more than $120 \mathrm{~ms}$ [9].

\section{Availability and Availability Versus Cost Studies}

Availability calculations are performed for the protected and unprotected SuperPON architectures following the methodologies of [15], [16]. Nodal and fiber unavailabilities, and hence MDTs, are calculated from mean time to repair (MTTR) values, and from equipment failure rates arising from the specific components and subsystems designed within PLANET. Simple probability expressions cater for duplicated fiber sections (e.g., feeder, D1) where required. Markov based state space methods are used to evaluate the MDTs appropriate to intranodal stages incorporating $N+1$ protection. One can then approximate that for the assumed small MDTs (i.e., unavailabilities $\ll 1$ ) that the SuperPON MDT is the sum of the MDTs for each functional block (node or fiber section).

The single AS approach was considered for simplicity, though the distributed approach is very similar in terms of availability (as opposed to survivability). Equipment failure rates were determined assuming that all active nodes are in controlled environments (i.e., ground benign), with the exception of the FTTC ONU which is not controlled (i.e., ground fixed), since the use of cooling fans in numerous large curb-side units would be noise polluting and require additional maintenance. The conservative and optimistic failure rates used for fiber cabling were average figures based on the experience of the operators within the PLANET consortium, while the conservative and optimized MTTR figures used arise from the (averaged) experience of the same operators. Fig. 8 shows the MDT results from using conservative MTTR and cable failure rates, and Fig. 9 shows the same arising from an optimized repair intervention strategy and with best case cable failure rates. A range of user densities are considered, which lead to different lengths of distribution fiber. Availability for the maximum distribution length $(10 \mathrm{~km})$ situation is also considered. The "unprotected" cases do include a double routed feeder whilst, where protection is indicated, it is the normal redundancy requirement of a double routed feeder and first distribution section along with $N+1$ protection of the OAs in the AS. From Fig. 8, it is seen that for all but the lowest user densities (and longest distribution) FTTH reaches the POTS target $(263 \mathrm{~min} / \mathrm{y})$ without the need of protection. With protection FTTH always reaches the POTS target and, in the best case, is quite near the target for leased lines ( $53 \mathrm{~min} / \mathrm{y}$ ). However unprotected FTTC fails the POTS target even in the best case, except at very high user densities, and protected FTTC makes the POTS target in the best case but not in the worst. For FTTC the normal redundancy requirement (i.e., that for FTTH) is thus not quite adequate. The intrinsic difference between the FTTC and FTTH results arises because FTTC has an additional node - the curbside ONU (note that the FTTH ONU is roughly equivalent to the VDSL NT in availability terms) which is also more complex, being co-located with the VDSL LIM (line interface module), and, unlike the FTTH ONU, is in an uncontrolled (ground fixed) environment for reasons stated earlier. Additional differences arise between the FTTC and FTTH results for the same user densities since the (15000 user) FTTC system will then have a longer distribution range than the (2048 user) FTTH system.

The impact of progressive redundancy is shown in Fig. 10 (for FTTH) and Fig. 11 (for FTTC). It is particularly important for FTTC given the normal redundancy requirement does not quite give FTTC the availability to support POTS. It is observed that FTTH can achieve the MDT necessary for leased lines (53 min/y) in the most redundant case, the residual MDT arising from the AS, the $\mathrm{SU}$, the ONU powering and a small contribution from the double routed feeder. This result is worse than that for two totally separate SuperPONs serving the same 


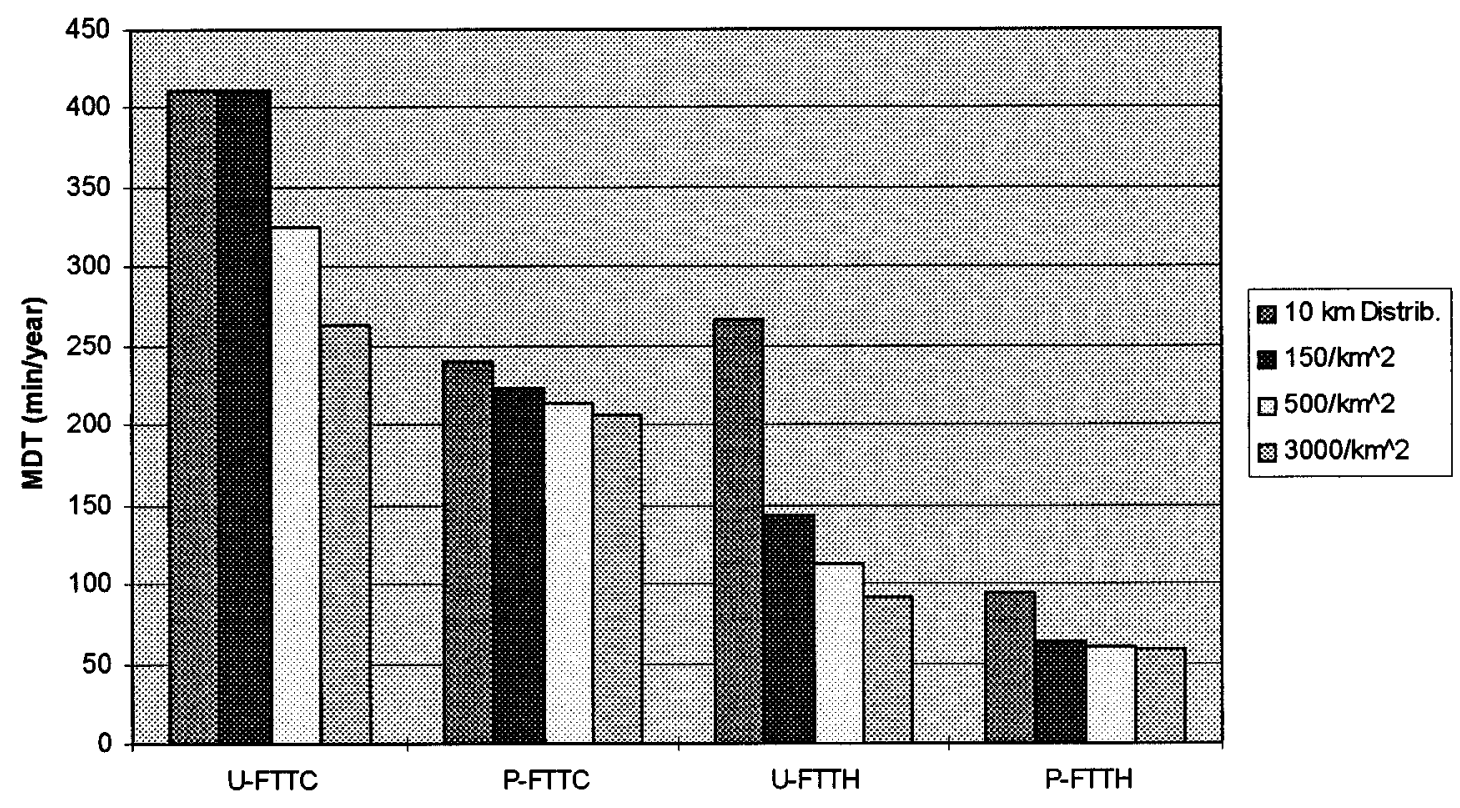

Fig. 9. MDT of various architectures $(\mathrm{min} / \mathrm{y})$ using optimized MTTR and best case fiber failure rates $(\mathrm{U}=$ unprotected apart from redundant feeder, $\mathrm{P}=$ protected with normal redundancy requirement).

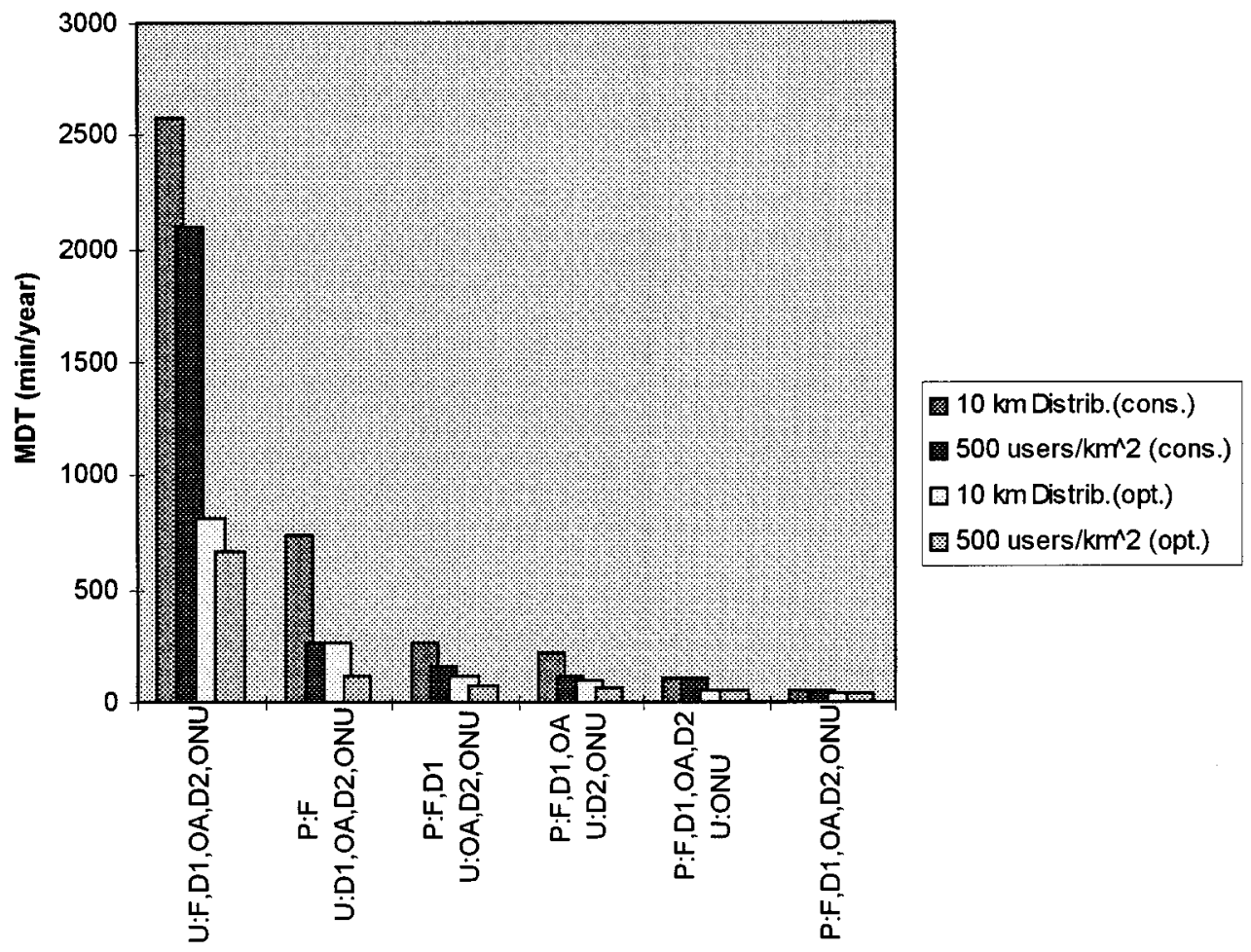

Fig. 10. $\mathrm{MDT}(\mathrm{min} / \mathrm{y})$ for various levels of protection of the FTTH SOA architecture $(\mathrm{U}=$ unprotected part, $\mathrm{P}=$ protected part $)$.

user, but has a lower component cost. Note also that the POTS target for FTTH can be reached with the feeder and D1 protected, but without also requiring OA protection. For FTTC the addition of $\mathrm{D} 2$ protection to the normal redundancy requirement allows the provision of POTS fairly comfortably in the optimized case, but just fails in the conservative case (but an average of the two cases would see POTS supported). If the ONU (including VDSL line interface modules) was also made redundant then FTTC comfortably supports POTS. By contrast if the
ONU was made redundant instead of D2 (no columns for this are shown) then FTTC can just support POTS.

To study availability versus cost normalized Year 2000 investment costs (as opposed to the costs of ownership [17]), comprising of civil work, cable and component costs, are considered. Of these cable costs, while not negligible, are the least significant. For FTTH civil works costs dominate whilst for FTTC there is more balance due to copper re-use by VDSL. Fig. 12 shows a scattergram of MDT versus normalized cost 


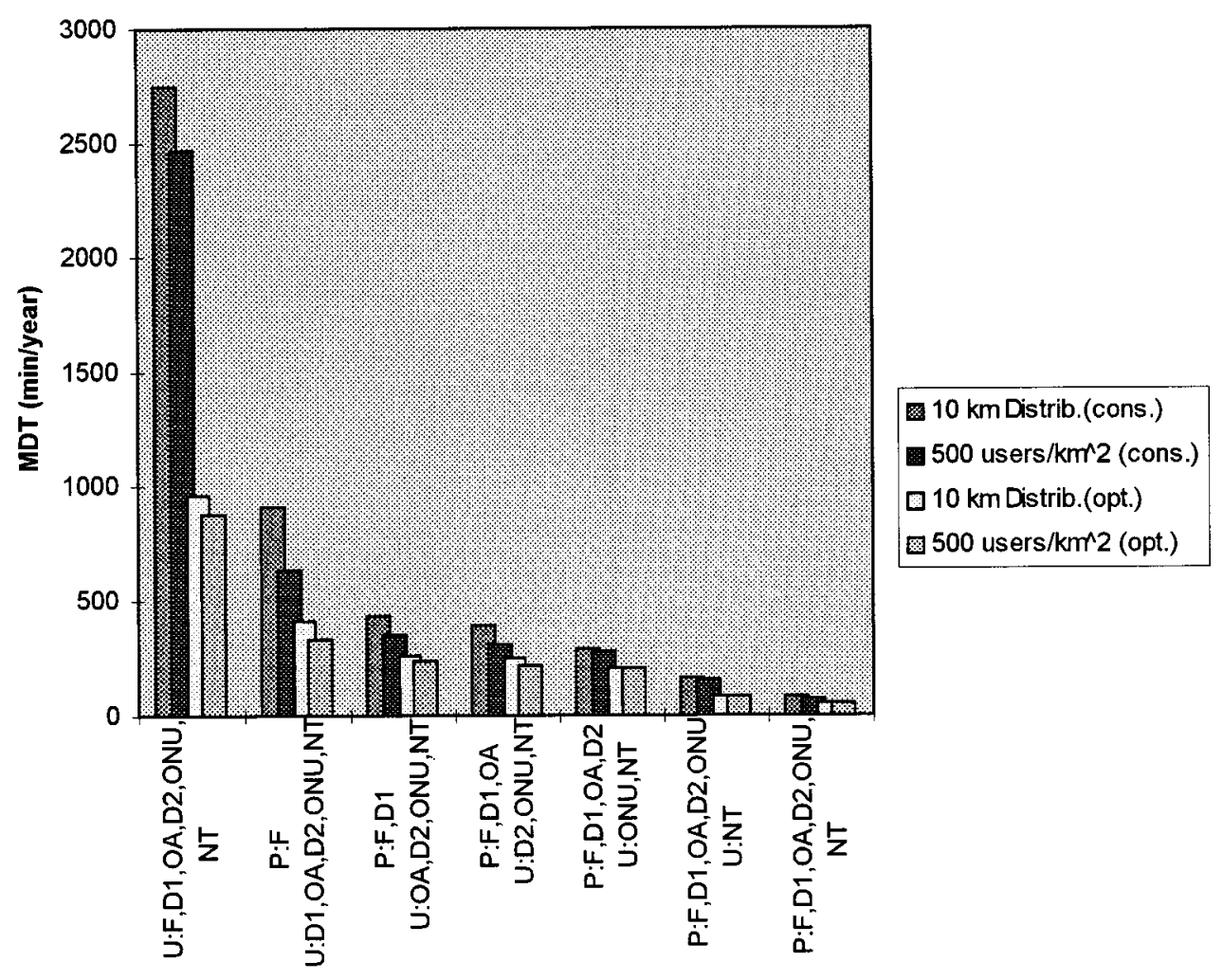

Fig. 11. MDT $(\mathrm{min} / \mathrm{y})$ for various levels of protection of the FTTC SOA architecture $(\mathrm{U}=$ unprotected part, $\mathrm{P}=$ protected part $)$.

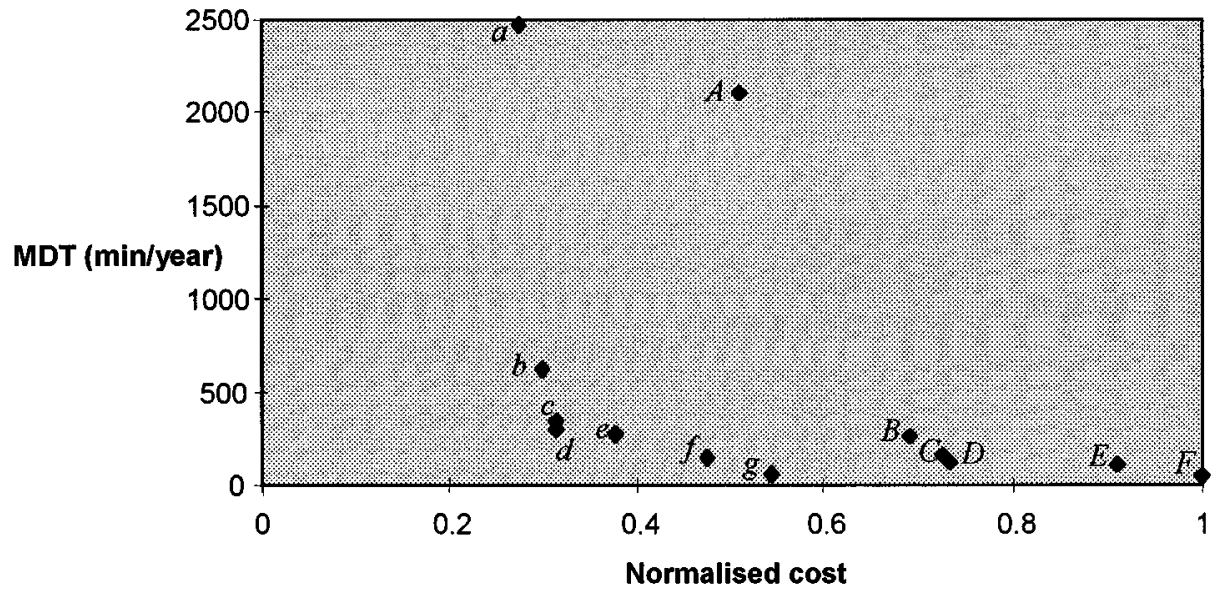

Fig. 12. MDT $(\mathrm{min} / \mathrm{y})$ versus normalized cost for the SOAlarchitecture with 500 users $/ \mathrm{km}^{2}$.(U = unprotected part, $\mathrm{P}=$ protected part)[FTTH: (A) U: F,D1,OA,D2,ONU, (B) P: F U: D1,OA,D2,ONU, (C) P: F,D1 U: OA,D2,ONU, (D) P: F,D1,OA U: D2,ONU, (E) P: F,D1,OA,D2 U: ONU, (F) P: F,D1,OA,D2,ONU] [FTTC: (a) U: F,D1,OA,D2,ONU,NT, (b) P: F U: D1,OA,D2,ONU,NT, (c) P: F,D1 U: OA,D2,ONU,NT, (d) P: F,D1,OA U: D2,ONU,NT, (e) P: F,D1,OA,D2 U: ONU,NT, (f) P: F,D1,OA,D2,ONU U: NT, (g) P: F,D1,OA,D2,ONU,NT].

for the FTTH and FTTC architectures, with 500 users $/ \mathrm{km}^{2}$ respectively, using results from conservative MDT calculations. For FTTH it can be seen that double routing the feeder gives the best decrease in MDT per unit cost (uc) increase (10 194 $\mathrm{min} / \mathrm{uc}$ ), while the duplication of D1 and the protection of OAs in the AS also yield good MDT decreases per cost increase. However, duplication of the ONU only has a MDT decrease of $600 \mathrm{~min} / \mathrm{UC}$, and duplication of D2 a decrease of $74 \mathrm{~min} / \mathrm{uc}$. For FTTC the MDT improvement per unit cost increase is generally more impressive, as would be expected given the additional infrastructure sharing. The feeder (73 $992 \mathrm{~min} / \mathrm{uc}$ ) is again most impressive, while the OAs and D1 are also very significant. The ONU (1263 min/uc) and the VDSL NT (1192 min/uc) are much less worthwhile duplicating, and D2 is again worst (522 $\mathrm{min} / \mathrm{uc}$ ). From these considerations of cost versus MDT it is verified that the normal requirement, identified in Table II, of making the feeder, D1 and the AS OAs redundant is reasonable in both FTTH and FTTC architectures. It is also seen that, for FTTH, duplication of D2 or the ONU is not particularly cost-effective, supporting their omission from the normal redundancy requirement identified in Table II. However FTTC, in particular, may require further redundancy. This can potentially be 
achieved more cost effectively by a redundancy of the FTTC ONU, though duplicating this without duplicating D2 may not be straightforward.

\section{CONCLUSIONS}

SuperPONs have been investigated in terms of redundancy provision and protection mechanisms. Various options for redundancy have been discussed and duplication of the feeder and first distribution section, and protection of the optical amplifiers in the AS, have been identified qualitatively and via availability calculations as forming part of the normal redundancy requirement provided to all attached users to facilitate appropriate availability of the basic telephony service. Dual homing was also described and the distributed AS solution was found to be more survivable than the single AS solution. The protection mechanisms necessary to automatically switch to the redundant provision have been discussed and calculated and, with the aid of suitable regular precautionary procedures, protection switching can generally be provided rapidly $(<50 \mathrm{~ms})$ for a commercial implementation of the SuperPON. Availability versus cost calculations have also been provided, demonstrating the decreasing benefit in mean down time per unit cost as the redundancy nears the user.

\section{ACKNOWLEDGMENT}

The authors acknowledge the valuable assistance of all the ACTS-PLANET consortium members, from Alcatel Telecom (Belgium), KPN (The Netherlands), Belgacom (Belgium), CSELT (Italy), Alcatel Optronics (France), Uniphase Netherlands BV (The Netherlands), IMEC (University of Ghent) (Belgium), Manchester Metropolitan University (U.K.), and National Technical University of Athens (Greece).

\section{REFERENCES}

[1] G. Van der Plas and I. Van de Voorde, "The evolution of the optical access network and the related technical issues," Proc. SPIE, vol. 2614, pp. 296-303, October 1995

[2] J. M. Senior, A. J. Phillips, and M. O. van Deventer, "Physical layer dimensioning of SuperPON architectures," Proc. SPIE, vol. 3230, pp. 198-205, November 1997.

[3] P. Crahay and E. Jaunart, "ATM SuperPON dimensioning for future residential and business users demand," in Proc. European Conf. Networks and Optical Communications (NOC'96), Heidelberg, Germany, June 1996.

[4] D. Faulkner, R. Mistry, T. Rowbotham, K. Okada, W. Warzanskyj, A. Zylbersztejn, and Y. Picault, "The full services access network initiative," IEEE Commun. Mag., vol. 35, no. 4, pp. 58-68, Apr. 1997.

[5] J. D. Angelopoulos, N. I. Lepidas, E. K. Fragoulopoulos, and I. S. Venieris, "TDMA multiplexing of ATM cells in a residential access SuperPON," IEEE J. Select. Areas Commun., vol. 16, no. 7, pp. 1123-1133, Sept. 1998.

[6] I. Van de Voorde and G. Van der Plas, "A novel ranging technique for an advanced optical network," in Tech. Dig. OFC'96 San Jose, CA, Feb./Mar. 1996, pp. 319-321.

[7] C. Coene, J. Codenie, P. Vaes, L. Wei, M. Valvo, R. Mercinelli, and I. Van de Voorde, "Spread spectrum coarse ranging techniques in optical access networks," in 5th Symp. Communications and Vehicular Technology in the Benelux, Enschede, The Netherlands, Oct. 1997.

[8] ITU-T, "Broadband optical access systems based on passive optical networks (PON),", ITU-T Recommendation G.983.1, Oct. 1998.
[9] J. L. De Groote, D. A. Buyse, H. K. Dedecker, F. M. Louagie, and H. F. Slabbinck, "Redundancy and protection-switching in APON systems," in Proc. European Conf. Networks and Optical Communications (NOC 99), vol. 1, Broadband Access and Technology, Delft, The Netherlands, June 1999, pp. 119-126.

[10] M. O. van Deventer, Y. M. van Dam, P. J. M. Peters, F. Vermaerke, and A. J. Phillips, "Evolution phases to an ultra-broadband access network: Results from ACTS-PLANET," IEEE Commun. Mag., vol. 35, no. 12, pp. 72-77, Dec. 1997.

[11] C. Coene, B. Stubbe, J. Codenie, R. Vlamnik, P. Vaes, X. Z. Qiu, J. Vandewege, C. Martin, H. Slabbinck, and P. Solina, "Uplink performance evaluation of super optical access networks," in Proc. European Conf. Optical Communication (ECOC'99), Nice, France, Sept. 1999, pp. 138-139.

[12] I. Van de Voorde, M. O. van Deventer, P. J. M. Peters, P. Crahay, E. Jaunart, A. J. Phillips, J. M. Senior, X. Z. Qiu, J. Vandewege, and P. J. Vetter, "Network topologies for SuperPON," in Tech. Dig. OFC'97, Dallas, TX, Feb. 1997, pp. 57-58.

[13] M. O. van Deventer, J. D. Angelopoulos, J. J. M. Binsma, A. J. Boot, P. Crahay, E. Jaunart, P. J. M. Peters, A. J. Phillips, X. Z. Qiu, J. M. Senior, M. Valvo, J. Vandewege, P. Vetter, and I. Van de Voorde, "Architectures for $100 \mathrm{~km} 2048$ split bidirectional SuperPON's from ACTS-PLANET,' Proc. SPIE, vol. 2919, pp. 242-251, Nov. 1996.

[14] ACTS-PLANET Consortium, "Access network architecture and feasibility,", deliverable report AC050/KPN/DR/I/W1D1/B1, May 1996.

[15] A. J. Phillips, J. M. Senior, P. J. Vetter, M. O. van Deventer, M. Valvo, and R. Mercinelli, "Reliability of SuperPON systems," in Proc. 6th IEE Conf. Telecommunications, Edinburgh, U.K., Mar./Apr. 1998, pp. 219-223.

[16] ITU-T, "Parameters and calculation methodologies for reliability and availability of fiber optic systems,", ITU-T Recommendation G.911, Apr. 1997.

[17] Y. M. van Dam, J. W. Pedersen, P. Vetter, R. de Brodt, T. van den Broeck, M. Valvo, and R. Mercinelli, "Cost of ownership for different PON architectures," in Tech. Dig. OFC'98, San Jose, CA, Feb. 1998, pp. 171-172.

A. J. Phillips, photograph and biography not available at the time of publication.

J. M. Senior, photograph and biography not available at the time of publication.

R. Mercinelli, photograph and biography not available at the time of publication.

M. Valvo, photograph and biography not available at the time of publication.

P. J. Vetter, photograph and biography not available at the time of publication.

C. M. Martin, photograph and biography not available at the time of publication.

M. O. van Deventer, photograph and biography not available at the time of publication.

P. Vaes, photograph and biography not available at the time of publication.

X. Z. Qiu, photograph and biography not available at the time of publication. 